GSA Data Repository 2016011

\title{
Seismically enhanced solute fluxes in the Yangtze River headwaters following the 2008 Wenchuan earthquake
}

\author{
Zhangdong Jin $^{1 *}$, A. Joshua West ${ }^{2}$, Fei Zhang1, Zhisheng An ${ }^{1}$, Robert G. Hilton ${ }^{3}$, \\ Jimin $\mathrm{Yu}^{4}$, Jin Wang ${ }^{1}$, Gen $\mathrm{Li}^{2}$, Li Deng ${ }^{1}$, and Xulong Wang ${ }^{1}$ \\ ${ }^{1}$ SKLLQG, Institute of Earth Environment, Chinese Academy of Sciences, Xi'an 710061, \\ China \\ ${ }^{2}$ Department of Earth Sciences, University of Southern California, Los Angeles, CA 90089, \\ USA \\ ${ }^{3}$ Department of Geography, Durham University, Durham DH1 3LE, UK \\ ${ }^{4}$ Research School of Earth Sciences, The Australian National University, Canberra, ACT \\ 2601, Australia
}




\section{METHODS}

Sampling and measurements. River water samples were collected weekly at the Weizhou and Zhenjiangguan Hydrological Stations between $7^{\text {th }}$ December 2009 and $26^{\text {th }}$ December 2011. In addition, paired samples were collected in 2011 from nine revisited sites (Fig. 1), matching sites that had been sampled at least once before the earthquake. All water samples were filtered in situ through $0.2 \mu \mathrm{m}$ Whatman ${ }^{\circledR}$ nylon filters. One 30 $\mathrm{mL}$ filtered un-acidified sample was collected for anion analysis, and one $60 \mathrm{~mL}$ sample for cation analysis was collected into a polyethylene bottle pre-cleaned with $6 \mathrm{M}$ quartz distilled $\mathrm{HNO}_{3}$ and acidified to $\mathrm{pH}<2$. Major cations were analyzed using a Leeman Labs Profile ICP-AES at the State Key Laboratory of Lake Science and Environment. Major anions $\left(\mathrm{Cl}^{-}\right.$and $\left.\mathrm{SO}_{4}{ }^{2-}\right)$ were determined using a Dionex-600 ion chromatography, and $\mathrm{HCO}_{3}{ }^{-}$was calculated from total inorganic carbon measurement on a Shimadzu Total Organic Carbon Analyzer (TOC-VCPH) at the Institute of Earth Environment, Chinese Academy of Sciences (IEECAS). The average replicate reproducibility was $0.5 \%-1 \%$ $(2 \sigma)$; charge balance $\left(\left(\mathrm{TZ}^{+}-\mathrm{TZ}^{-}\right) /\left(\mathrm{TZ}^{+}+\mathrm{TZ}^{-}\right)\right)$was within $10 \%$ for all but 3 of the 245 samples analyzed, and in most cases was $<5 \%$. For Sr isotope analysis, water samples containing $400 \mathrm{ng}$ Sr were evaporated to dryness in ultraclean Teflon vessels and re-dissolved in $1 \mathrm{~mL} 3 \mathrm{M} \mathrm{HNO}_{3}$. Strontium was then separated by passing through an Eichrom $\mathrm{Sr}^{\mathrm{SPEC}}$ exchange column pre-conditioned with $3 \mathrm{M} \mathrm{HNO}_{3}$ and eluted with $4 \mathrm{~mL}$ ultra high quality deionised water. ${ }^{87} \mathrm{Sr} /{ }^{86} \mathrm{Sr}$ was measured using a Neptune-plus MC-ICP-MS at the IEECAS. The measured ${ }^{87} \mathrm{Sr} /{ }^{86} \mathrm{Sr}$ ratio was normalized (assuming ${ }^{86} \mathrm{Sr} /{ }^{88} \mathrm{Sr}=0.1194$ ), and the mean ${ }^{87} \mathrm{Sr} /{ }^{86} \mathrm{Sr}$ ratio of the NBS 987 standard (recommended value $=0.710245)$ obtained during analysis was $0.710249 \pm 0.000008(2 \sigma, \mathrm{n}=6)$. 
Data compilation. All data on river water chemical compositions prior to the 2008 Wenchuan earthquake shown in Figures 2 and 3 were compiled from published literature (Qin et al., 2006; Yoon et al., 2008; Huh, 2010). These data were collected in different years, used same filtration methods and measured cation concentrations and ${ }^{87} \mathrm{Sr} /{ }^{86} \mathrm{Sr}$ ratios at different labs. Consistent ratios and seasonal variations suggest that the comparisons of post-earthquake data with these pre-earthquake data are robust.

\section{Estimation of net $\mathrm{CO}_{2}$ consumption associated with silicate alkalinity $\left(\varnothing \mathrm{CO}_{2}\right)$. A} forward model (Galy and France-Lanord, 1999) was employed to calculate the ionic fractions derived from silicate weathering after correcting for rainwater and evaporite corrections. Assuming that all $\mathrm{Cl}^{-}$comes from rainwater and halite, $\mathrm{Na}^{*}\left(\mathrm{Na}^{*}=\mathrm{Na}_{\text {river }}-\right.$ $\mathrm{Cl}_{\text {river }}$ ) was considered to be derived from silicate sources because $\mathrm{Na}$ is not present in carbonates (Gaillardet et al., 1999). The rainwater contribution to other major cations was corrected using the measured cation $/ \mathrm{Cl}^{-}$ratios in rain samples, since $\mathrm{Cl}^{-}$is generally conservative. Ten rain samples were collected during March and September 2010 (Table DR4), which had an average weighted $\mathrm{Cl}^{-}$content of $21.3 \mu \mathrm{mol} / \mathrm{L}$ (multiplied average $\mathrm{Cl}^{-}$ content in rainwater by concentration factor). The fractions of rainwater-corrected dissolved $\mathrm{K}, \mathrm{Ca}$ and $\mathrm{Mg}$ derived from silicate weathering were calculated, assuming that the cations were released to rivers from silicates in a fixed proportion relative to $\mathrm{Na}^{*}$. Finally, $\varnothing \mathrm{CO}_{2}$ was calculated based on these silicate cations, coupled with the data of drainage areas $(A)$ and water discharges $(Q)$ :

$$
\varnothing \mathrm{CO}_{2}=\varnothing\left(\mathrm{K}_{\text {sil }}+\mathrm{Na}^{*}+2 \times \mathrm{Ca}_{\text {sil }}+2 \times \mathrm{Mg}_{\text {sil }}\right) \times \mathrm{Q} / \mathrm{A}
$$

The endmember silicate ratios used in the calculations were 0.7 for $\mathrm{Ca} / \mathrm{Na}$ and 0.3 for $\mathrm{Mg} / \mathrm{Na}$ (Qin et al., 2006); these end-member ratio values do not affect the relative 
magnitudes of $\varnothing \mathrm{CO}_{2}$ before and after the earthquake, assuming the composition of silicate minerals did not change. 


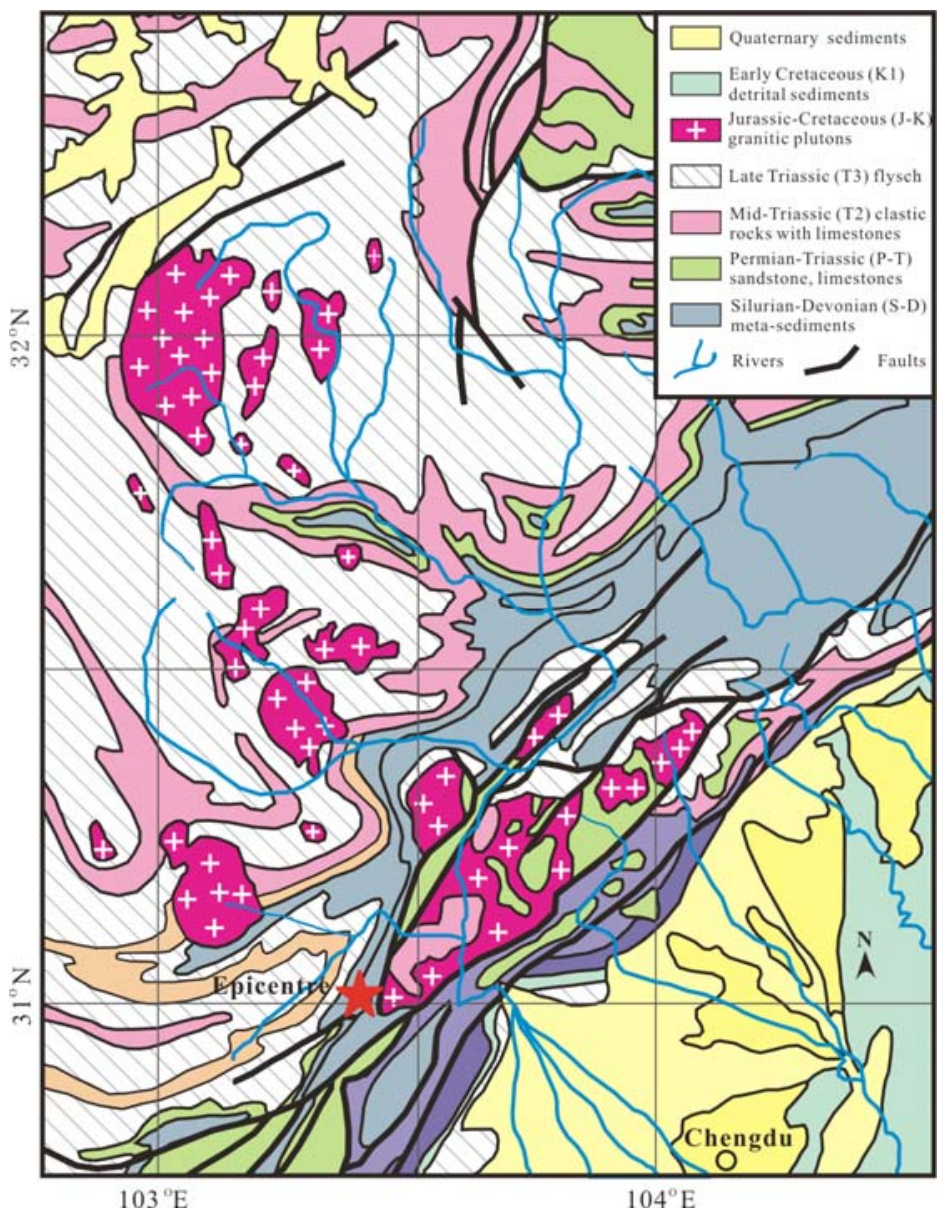

Figure DR1: Geological map of the middle and upper reaches of the Min Jiang river basin (modified from Bureau of Geology and Mineral Resources of Sichuan Province, 1991), showing major lithologies, faults, and the epicenter of the $2008 M_{\mathrm{w}} 7.9$

Wenchuan earthquake. 

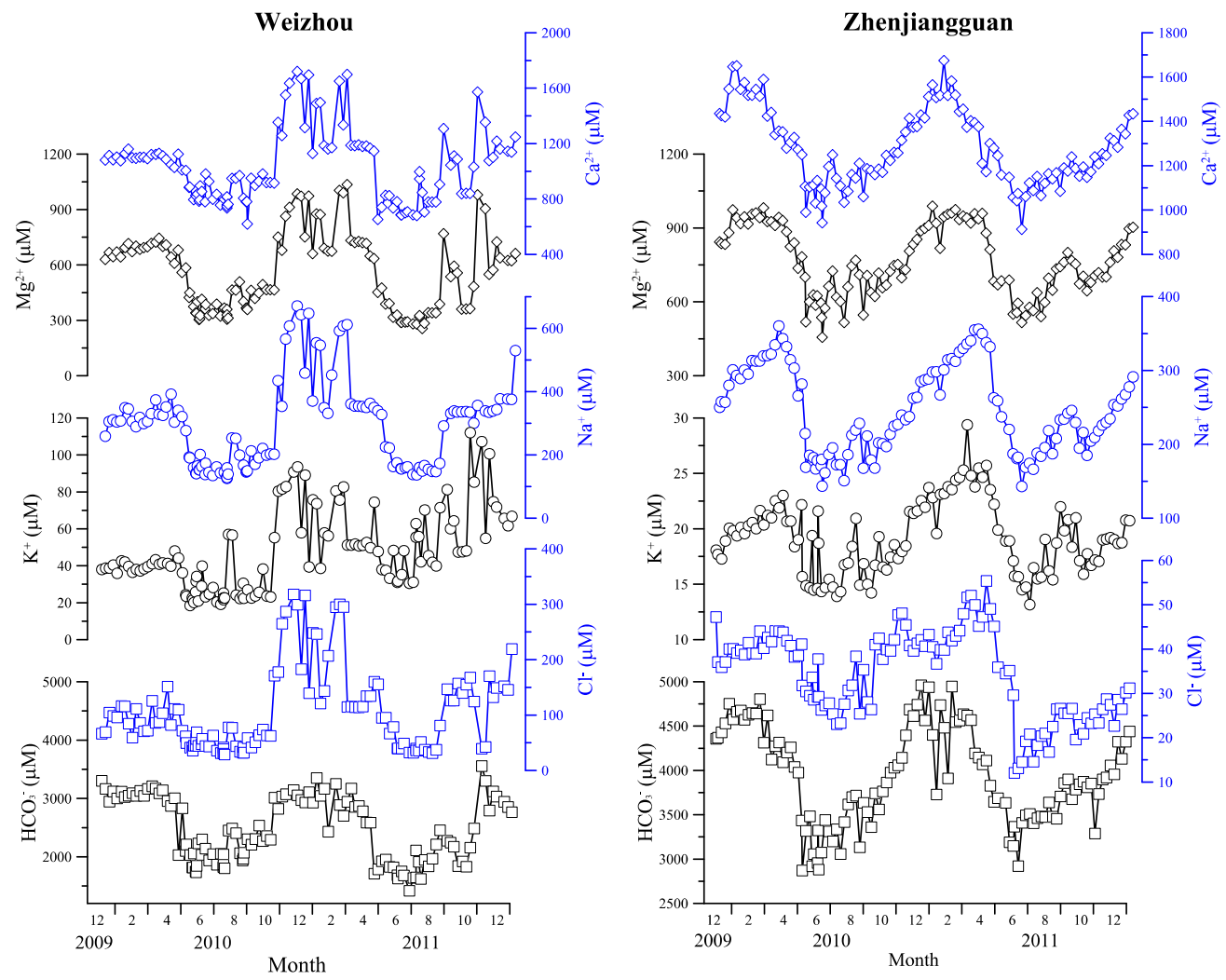

Figure DR2: Annual temporal variations in concentrations of dissolved major ions $\left(\mathrm{Ca}^{2+}, \mathrm{Mg}^{2+}, \mathrm{Na}^{+}, \mathrm{K}^{+}, \mathrm{Cl}^{-}\right.$, and $\left.\mathrm{HCO}_{3}{ }^{-}\right)$in Minjiang river water during late 2009 and 2011. Water samples were collected weekly between $7^{\text {th }}$ December 2009 and $26^{\text {th }}$ December 2011 at the Weizhou and Zhenjiangguan hydrological stations. 

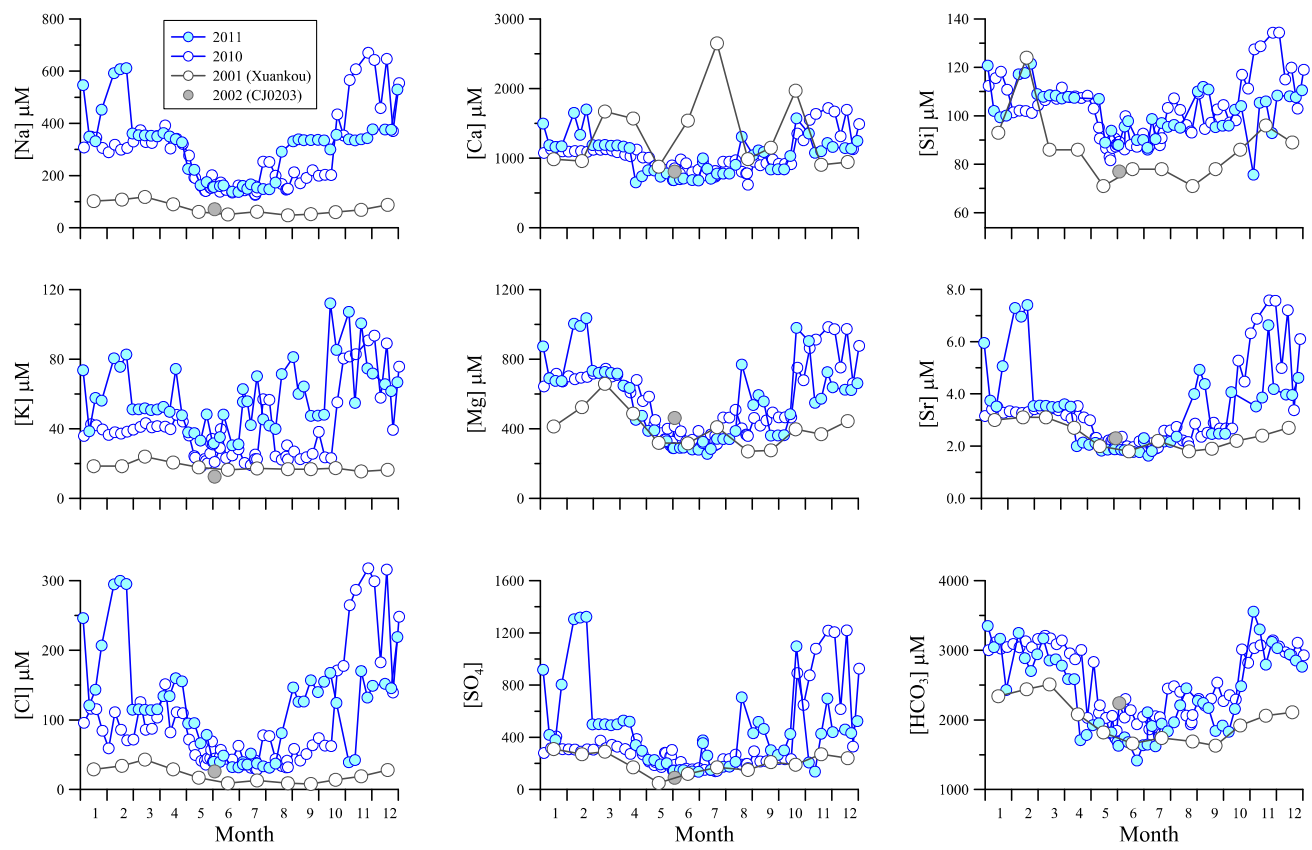

Figure DR3: Observed major ionic concentrations at Weizhou in 2010-2011, as compared to 2001-2002 when samples were collected by Qin et al. (2006). The 2001 time series were collected at Xuankou, slightly downstream of Weizhou. Grey dot shows the values of the single sample (CJ0203) collected at the Weizhou site in May 2002 by Qin et al. (2006). For many elements (e.g. $\mathrm{Mg}^{2+}, \mathrm{Ca}^{2+}, \mathrm{Sr}^{2+}$ ), the values in 2001-2002 are generally very similar to those from 2010-2011, but for other elements (e.g. $\mathrm{Na}^{+}, \mathrm{Si}$ ) the water chemistry at the two times is clearly distinct. 

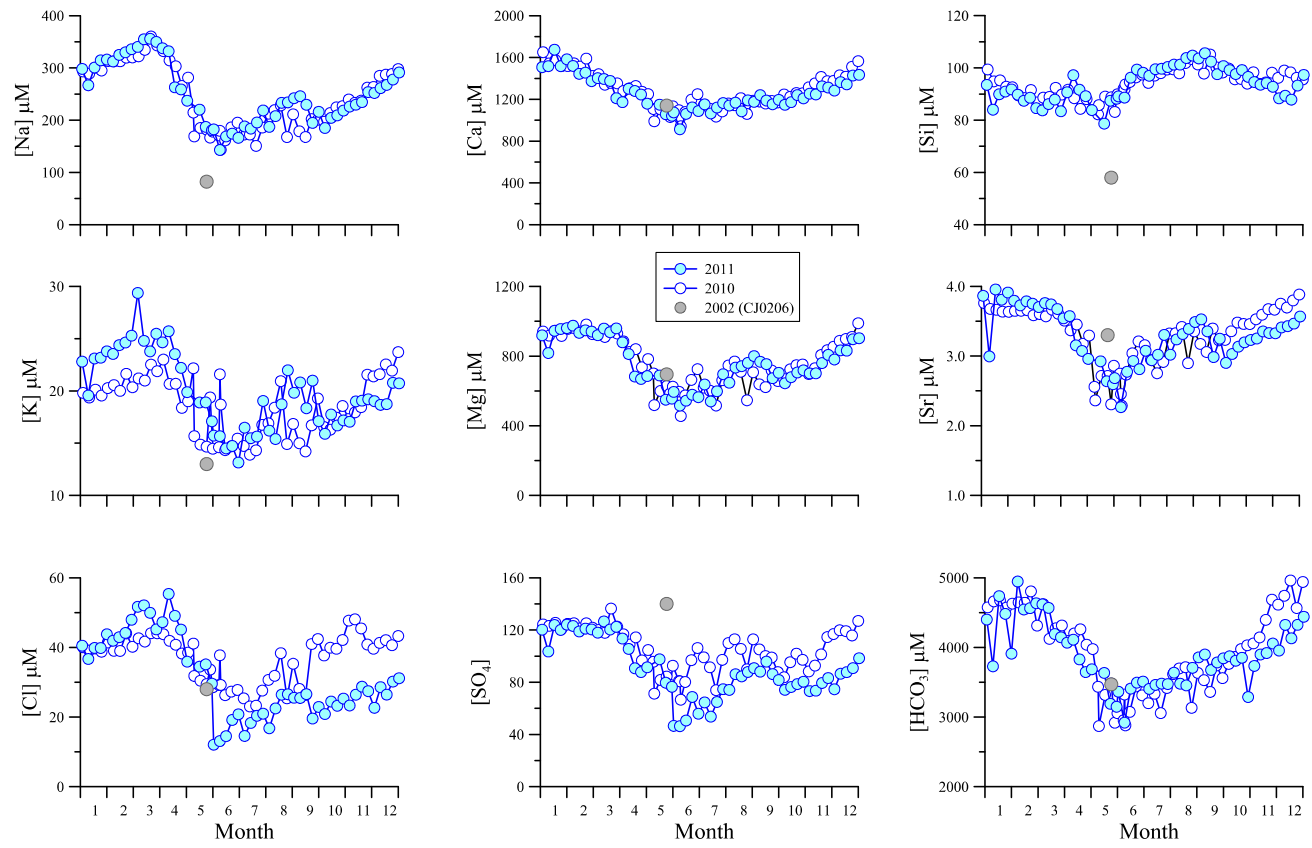

Figure DR4: Time series of major ionic concentrations at Zhenjiangguan in 2010-2011, as compared to 2002 when the CJ0206 sample was collected from main stem at Zhenjiangguan by Qin et al. (2006). The values for most ions in CJ0206 are generally simile to the samples collected in 2010-2011, with the notable exceptions of $\mathrm{Na}^{+}, \mathrm{Si}$, and $\mathrm{SO}_{4}{ }^{2-}$. 

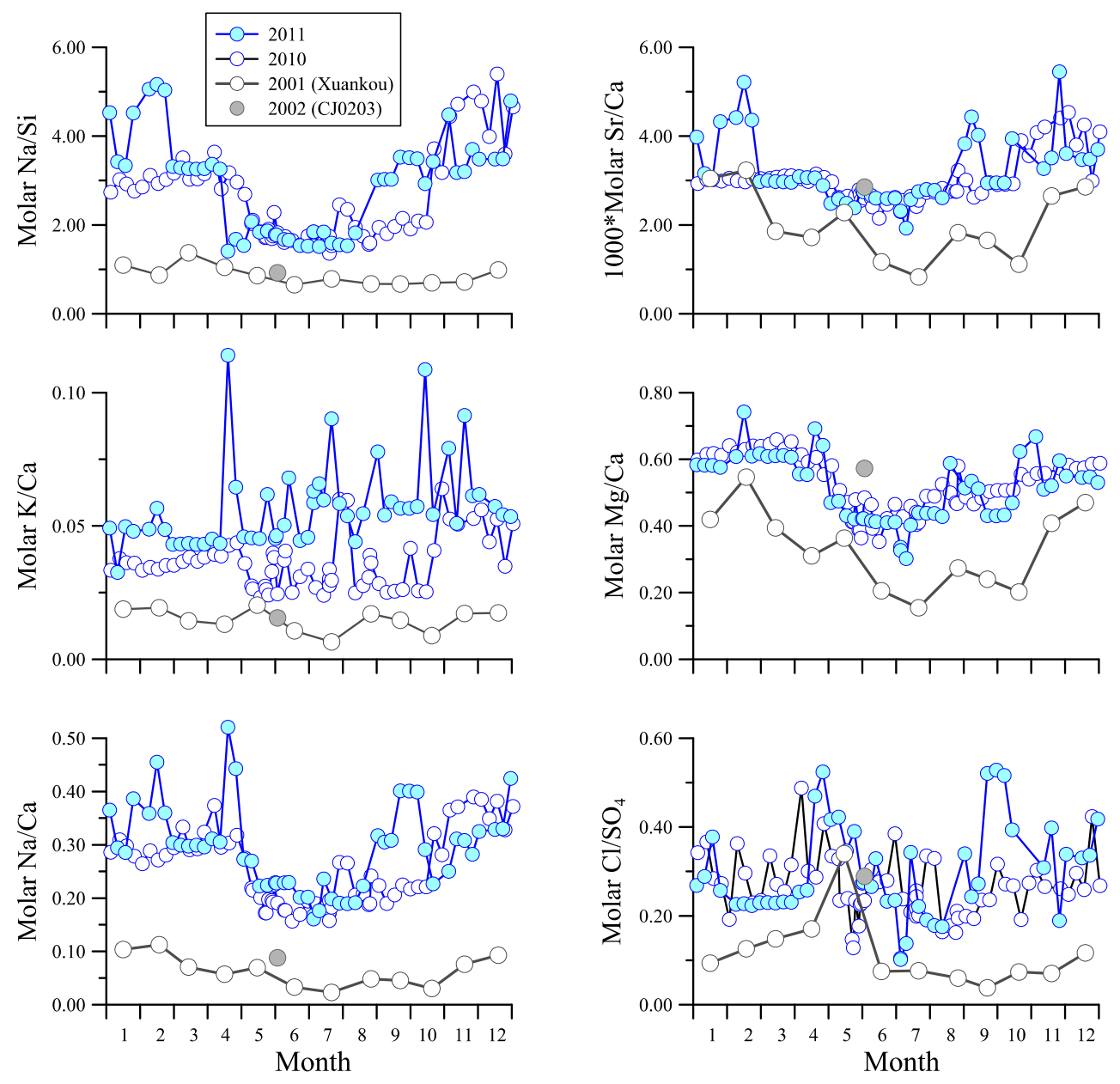

Figure DR5: Comparison of observed major ionic ratios at Weizhou in 2010-2011, as compared to 2001-2002 when samples were collected by Qin et al. (2006). Several of the ratios in 2001-2002 are chemically distinct from the samples collected in 2010-2011 at this site, in the middle of the region strongly affected by the 2008 earthquake. 

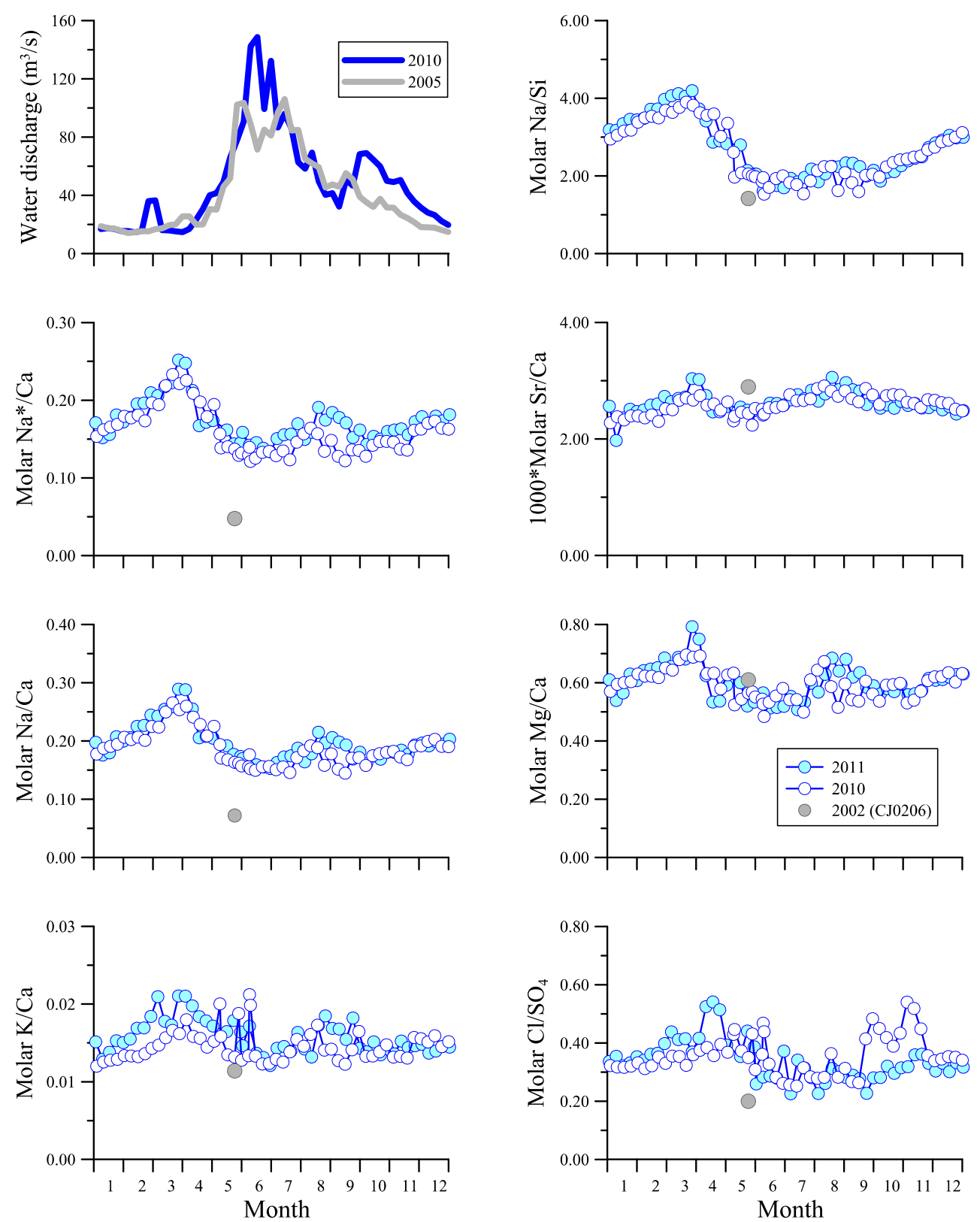

Figure DR6: Time series of observed major ionic ratios at Zhenjiangguan in 2010-2011, as compared to 2002 when the CJ0206 sample (grey dot) was collected from the Min Jiang main stem at Zhenjiangguan by Qin et al. (2006), along with water discharge in 2005 and 2010 at Zhenjiangguan station. Most of the elemental ratios in CJ0206 are close to those in samples collected in 2010-2011, except for slightly elevated $\mathrm{Na} / \mathrm{Ca}$ and $\mathrm{Na} / \mathrm{Ca}$ in the post-earthquake samples. 


\section{REFERENCES CITED}

Gaillardet, J., Dupré, B., Louvat, P., and Allègre, C., 1999, Global silicate weathering and $\mathrm{CO}_{2}$ consumption rates deduced from the chemistry of large rivers. Chemical Geology, v. 159, p. 3-30, doi:10.1016/S0009-2541(99)00031-5.

Galy, A., and France-Lanord, C., 1999, Weathering processes in the Ganges-Brahmaputra basin and the riverine alkalinity budget. Chemical Geology, v. 159, p. 31-60, doi:10.1016/S0009-2541(99)00033-9.

Huh, Y., 2010, Estimation of atmospheric $\mathrm{CO}_{2}$ uptake by silicate weathering in the Himalayas and the Tibetan Plateau: a review of existing fluvial geochemical data. Geological Society, London, Special Publications, v. 342, p. 129-151, doi:10.1144/SP342.10.

Qin, J., Huh, Y., Edmond, J., Du, G., and Ran, J., 2006, Chemical and physical weathering in the Min Jiang, a headwater tributary of the Yangtze River. Chemical Geology, v. 227, p. 53-69, doi:10.1016/j.chemgeo.2005.09.011.

Yoon, J., Huh, Y., Lee, I., Moon, S., Noh, H., and Qin J., 2008, Weathering processes in the Min Jiang: major elements, ${ }^{87} \mathrm{Sr} /{ }^{86} \mathrm{Sr} ; \delta^{34} \mathrm{~S}_{\mathrm{SO} 4}$; and $\delta^{18} \mathrm{O}_{\mathrm{SO} 4}$. Aquatic Geochemistry, v. 14 , p. 147-170, doi:10.1007/s10498-008-9030-7. 